\title{
Hemispherical Brain Dominance and Academic Achievement among Nursing Students
}

\author{
Essmat A Mansour ${ }^{1}$, Maha El-Araby ${ }^{2}$, Isabelita N Pandaan ${ }^{1}$, \\ Essmat M Gemeay ${ }^{3}$ \\ ${ }^{I}$ Medical Surgical Nursing Department. King Saud University, College of Nursing, Saudi Arabia, \\ ${ }^{2}$ Maternity and Pediatric Nursing Department .King Saud University, College of Nursing. Saudi Arabia and \\ pediatric Nursing Department. College of Nursing .Tanta University .Egypt . \\ ${ }^{3}$ Psychiatric Nursing Department, Tanta University, College of Nursing, Egypt
}

\begin{abstract}
Different brain dominance among individuals is a widely accepted and known fact, in which each hemisphere of the brain contributes to certain body functions, each person has the unique ways of perceiving, interpretations and utilization of a given information and it may affect the student's achievement.

Aim of this study is to investigate the hemispherical brain dominance and its relation with the academic achievements among nursing students.

Methods; A descriptive correlational study was conducted at college of nursing .Tanta University, Egypt during the academic year 2016-2017 on 151 students. Torrance hemispheric brain dominance scale which was developed by Roger Tylor and updated by Paul Torrance 1980 was used to collect data.

Results of this study revealed that $61.6 \%$ of the total sample were right side brain dominance, also a statistical significant difference were found between grade point average and brain dominance, meanwhile a positive correlation between birth order, grade point average and preferred specialty before joining to nursing with brain dominance .

Conclusion the current study revealed a relation between academic achievement and brain dominance among nursing students.
\end{abstract}

Key words: Hemispherical brain dominance, academic achievement \& nursing students

\section{Introduction}

Brain hemisphericity referred to the idea that people rely on a preferred mode of cognitive processing that is linked to predominant activity of either their left or right cerebral hemisphere. Individual hemisphericity was erroneously thought to be located somewhere on a gradient between right and left brain dominance with most people being intermediate ${ }^{(1)}$. Cognitive neuroscientists generally held that brain hemisphericity or brain dominance is the tendency of an individual to process information through the left hemisphere or the right hemisphere or in combination ${ }^{(2)}$. Different brain dominance among individuals is a widely accepted and known fact, in which each hemisphere of the brain contributes to certain body functions, each person has the unique ways of perceiving, interpretations and utilization of a given information ${ }^{(3)}$

Academic achievement represents performance outcomes that indicate the extent to which a person has accomplished specific goals that were the focus of activities in instructional environments, specifically in school, college, and university ${ }^{(4)}$. There is no agreement on how the academic achievement is best tested or which aspects are most important, but, it is commonly measured by examination or continuous assessment and the student's grade is considered the main indicator for academic achievement ${ }^{(5)}$.

Previous studies has found that hemispherical brain dominance has a significant influence on student's outcome and achievements, in which student's achievement is the outcome of education, it is the extent to which a student, teacher or institution has achieved their educational goals ${ }^{(6,7)}$.

Researchers proof that there are many specific differences between the two hemispheres, the right brain is better at copying of designs, discrimination of shapes, understanding geometric properties, reading faces, music ,global holistic processes, expressing and reading emotions in which the left brain is better at language skills, skilled movement and analytical time sequence process ${ }^{(8)}$.

At academic settings of nursing education, the teachers must help achieve a balance among the varieties of students regarding the hemispherical brain dominance to ensure that the students made learning flow. Today's society is in the information age. How to utilize the vast amount of information that is being generated every day for problem-solving is important in higher education. There are critical thinking and effective communication and problem-solving abilities as indicators of success in higher education and the challenge here is how to utilize this information revolution considering the individual differences at the same time ${ }^{(9)}$. 
Nursing study requires special capabilities because of the diversity and complexity of nursing practice make it necessary to prepare nurses who can think critically and creatively, and who have a sound education in nursing, science, and the humanities, so the teacher of nursing should find a teaching styles which will suit all students with their diversity of hemispherical brain dominance to ensure that the processes of teaching and learning will correctly takes place and will reflected on the student's outcome. Therefore It is, important to investigate the hemispherical brain dominance and its relationship the academic achievement among nursing students.

Aim of the study

The aim of this study is to investigate the hemispherical brain dominance and its relation with the academic achievements among nursing students.

\section{Research Methodology}

The researchers' hypothesis that there is a relation between hemispherical brain dominance and academic achievement. Research question: is there a relationship between hemispheric brain dominance and student's academic achievements? A total sample of 151 students were recruited in this study enrolled in the eight levels of college of nursing and represent the total numbers of students in year 2016-2017

A descriptive correlational study was conducted at college of nursing .Tanta University, Egypt during the academic year 2016-2017

Two tools were used to conduct the current study first is a structured interviewing questionnaire were designed by the researchers to collect the socio- demographic data as : age, educational level, parent's educational level, favorite hobbies, preferred course before joining nursing etc ....And the second is Torrance hemispheric brain dominance scale which was developed by Roger Tylor and updated by Paul Torrance 1980 (10) it was consists of 50 multiple choices questions including: way of memorizing, thinking, preferred learning style ....etc and according to the respondent's answer calculation must be done to determine if the respondent right, left or whole brain dominance, the calculation was made according to the following scoring system ;

Compute the B score $\sim$ the A score. It can be a minus or plus.

If the $\mathrm{C}$ score is 15 or higher, divide the $\mathrm{B}$ minus $\mathrm{A}$ score

By 3. Round the score to the nearest number. The answer will be the gained score. It can be a minus or plus number.

OR

If the $\mathrm{C}$ score is from 9 to 14 , divide the $\mathrm{B}$ minus $\mathrm{A}$ score by 2 . The answer will be the gained score. It can be a minus or plus answer.

If the $\mathrm{C}$ score is less than 9, do not divide at all. The B minus A score is the gained score Plot the score below

A score of $10=$ Whole brain dominance

A score of -1 to $-6=$ Whole brain dominance favoring the left

A score of +1 to $+6=$ Whole brain dominance favoring the right

A score of -7 or lower $=$ Left brain dominance

A score of +7 or higher $=$ Right brain dominance

Data were collected by the researchers after obtaining an official approval from the dean of the college and also from the students participating in the study. Students were interviewed on individual base, the time needed to fill out the questionnaire was 30 minutes. Student's performance and acheivemniets were collected from the student's files from the student's affaire department.

\section{Filed work}

1. Official permission to carry out the study from the responsible authoritative was obtained.

2. Students included in the study were identified

3. Student's consent was obtained to participate in the study after explaining the aim of study and complete disclosure of the study was assured.

4. Hemispheric brain dominance test, was used to collect the needed data.

5. Data collection:

6. Data was collected within 4 month's period in the college of nursing, from the beginning of December 2016 to the end of March 2017.

\section{Statistical Analysis}

Data entry and statistical analysis was performed utilizing the Statistical Package for Social Sciences (SPSS) software package. Various statistical tools were applied to derive results from the data gathered. Descriptive statistics in the form of frequencies and percentages are presented to reflect the demographic 
characteristics of the studied sample. Whereas, Mann Whitney U test (differences for 2 groups), Kruskall wallis test (difference between 3 groups) were used to determine significant differences. Furthermore, Correlation Spearman rho correlation coefficient determined statistical relationships.

\section{Demographic Characteristics}

\section{Results}

There were 151 participants in this study. From the profile of the studied sample, in terms of birth order, most of the participants (47\%) are middle children in birth position. Meanwhile, $48.3 \%$ have fathers who have university level education while $43 \%$ have mothers who have primary level of education. Furthermore, $36.4 \%$ of the respondents preferred music as their favorite hobby. Currently, a number of the participants $(31.8 \%)$ are in the sixth (6th) level of study. However, 49 from 151 (32.5\%) preferred medicine course before joining nursing. With regards to the level of hemispherical brain dominance, more than half (61.6\%) belongs to the right brain dominance. The mean age from among the study sample is $20.87(\mathrm{SD}=3.09)$ and the level of academic achievement (Grade point average) is $3.69(\mathrm{SD}=1.63)$.

Table 1. Demographic characteristics of the studied sample $(\mathrm{N}=151)$

\begin{tabular}{|c|c|c|c|}
\hline \multirow{2}{*}{\multicolumn{2}{|c|}{$\begin{array}{l}\text { Profile } \\
\text { Birth order }\end{array}$}} & \multirow{3}{*}{$\begin{array}{l}\text { f } \\
54\end{array}$} & \multirow{3}{*}{$\begin{array}{l}\% \\
35.8\end{array}$} \\
\hline & & & \\
\hline & First & & \\
\hline & Middle & 71 & 47.0 \\
\hline & Last & 26 & 17.2 \\
\hline \multicolumn{4}{|c|}{ Father's educational level } \\
\hline & Read \& write / primary & 25 & 16.6 \\
\hline & Secondary & 53 & 35.1 \\
\hline & University & 73 & 48.3 \\
\hline \multicolumn{4}{|c|}{ Mother's educational level } \\
\hline & Read \& write / primary & 65 & 43.0 \\
\hline & Secondary & 35 & 23.2 \\
\hline & University & 50 & 33.1 \\
\hline \multicolumn{4}{|c|}{ Favorite hobbies } \\
\hline & Reading & 33 & 21.9 \\
\hline & Drawing / painting & 21 & 13.9 \\
\hline & Music & 55 & 36.4 \\
\hline & Science & 7 & 4.6 \\
\hline & Art & 33 & 21.9 \\
\hline \multicolumn{4}{|c|}{ Current level of study } \\
\hline & 3 & 7 & 4.6 \\
\hline & 4 & 18 & 11.9 \\
\hline & 5 & 16 & 10.6 \\
\hline & 6 & 48 & 31.8 \\
\hline & 7 & 46 & 30.5 \\
\hline & 8 & 16 & 10.6 \\
\hline \multicolumn{4}{|c|}{ Preferred course before joining Nursing } \\
\hline & Pharmacy & 11 & 7.3 \\
\hline & Applied science & 48 & 31.8 \\
\hline & Medicine & 49 & 32.5 \\
\hline & Dentistry & 26 & 17.2 \\
\hline & Science & 10 & 6.6 \\
\hline & Other & 7 & 4.6 \\
\hline \multicolumn{4}{|c|}{ Level of hemispherical brain dominance } \\
\hline & Whole brain dominance favoring the left & 24 & 15.9 \\
\hline & Whole brain dominance favoring the right & 32 & 21.2 \\
\hline & Left brain dominance & 2 & 1.3 \\
\hline & Right brain dominance & 93 & 61.6 \\
\hline \multicolumn{4}{|l|}{ Age } \\
\hline & \multicolumn{3}{|l|}{ Mean $=20.87 ;$ Std Deviation $=3.09$} \\
\hline \multicolumn{4}{|c|}{ Level of academic achievement [Grade point average (GPA)] } \\
\hline & Mean $=3.69 ;$ Std Deviation $=1.63$ & & \\
\hline
\end{tabular}

Significant differences between demographic characteristics and hemispheric brain dominance

Among the selected participants' characteristics, hemispheric brain dominance statistically, and significantly differed in their grade point average $(\mathrm{p}=0.009 ; 95 \% \mathrm{CI}=.005, .009)$. However, the characteristics in terms of age, birth order, favorite hobbies and preferred specialty before joining nursing showed no significant statistical difference (see Table 2). 
Hemispherical brain dominance and academic achievement among nursing students

Table 2. Differences between profile and hemispheric brain dominance $(\mathrm{N}=151)$

\begin{tabular}{|l|l|l|l|}
\hline & $\chi^{2}(\mathrm{df} 3)$ & $p$-value & $95 \%$ CI \\
\hline Age & 5.15 & 0.161 & $.148, .162$ \\
\hline Birth order & 4.61 & 0.203 & $.205, .221$ \\
\hline Favorite hobbies & 0.47 & 0.925 & $.922, .932$ \\
\hline Preferred specialty before joining nursing & 5.44 & 0.142 & $.114, .127$ \\
\hline Grade point average & 11.52 & $0.009 * *$ & $.005, .009$ \\
\hline
\end{tabular}

**Significant at $p<0.01$

Correlation analysis between demographic characteristics and hemispheric brain dominance

Table 3 shows that birth order $(\mathrm{r}=.16 ; \mathrm{p}=0.04)$; preferred specialty before joining nursing $(\mathrm{r}=.17 ; \mathrm{p}=0.05)$ and grade point average $(\mathrm{r}=-.19 ; \mathrm{p}=0.02)$ were statistically and significantly associated with brain dominance. Whereas, age, father's education level, mother's educational level, favorite hobbies and current level of study showed no significant relationship in the level of hemispheric brain dominance of the studied sample.

Table 3. Correlation results between demographic characteristics of the studied group and the level of hemispheric brain dominance $(\mathrm{N}=151)$.

\begin{tabular}{|c|c|c|c|c|c|c|c|c|c|}
\hline & & $\begin{array}{l}\text { Brain } \\
\text { dominance }\end{array}$ & $\begin{array}{l}1 \\
\text { Age }\end{array}$ & $\begin{array}{l}2 \\
\text { Birth } \\
\text { order }\end{array}$ & $\begin{array}{l}3 \\
\text { Father's } \\
\text { education } \\
\text { level }\end{array}$ & $\begin{array}{l}4 \\
\text { Mother's } \\
\text { education } \\
\text { level }\end{array}$ & $\begin{array}{l}5 \\
\text { Favorite } \\
\text { hobbies }\end{array}$ & $\begin{array}{l}6 \\
\text { Current level } \\
\text { of study }\end{array}$ & $\begin{array}{l}7 \\
\text { Preferred } \\
\text { before jpecialty } \\
\text { nursing }\end{array}$ \\
\hline \multirow[t]{2}{*}{1} & $r^{\dagger}$ & -0.16 & & & & & & & \\
\hline & $p^{\dagger \dagger}$ & 0.06 & & & & & & & \\
\hline \multirow[t]{2}{*}{2} & $r$ & $0.16^{*}$ & -0.08 & & & & & & \\
\hline & $p$ & 0.04 & 0.33 & & & & & & \\
\hline \multirow[t]{2}{*}{3} & $r$ & 0.06 & $-.325^{* \ldots * k}$ & -0.05 & & & & & \\
\hline & $p$ & 0.49 & 0.000 & 0.58 & & & & & \\
\hline \multirow[t]{2}{*}{4} & $r$ & 0.08 & $-.435^{* * * *}$ & -0.13 & $.554^{* * * *}$ & & & & \\
\hline & $p$ & 0.32 & $<0.001$ & 0.11 & $<0.001$ & & & & \\
\hline \multirow[t]{2}{*}{5} & $r$ & 0.01 & -0.11 & -0.07 & 0.10 & $.267^{* *}$ & & & \\
\hline & $p$ & 0.92 & 0.17 & 0.37 & 0.21 & 0.001 & & & \\
\hline \multirow[t]{2}{*}{6} & $r$ & -0.08 & $.724^{* * * *}$ & -0.05 & $-.341^{* * * *}$ & $-.400^{* * *}$ & 0.02 & & \\
\hline & $p$ & 0.33 & $<0.001$ & 0.52 & $<0.001$ & $<0.001$ & 0.78 & & \\
\hline \multirow[t]{2}{*}{7} & $r$ & $0.17^{*}$ & -0.09 & 0.02 & 0.05 & 0.07 & -0.03 & 0.01 & \\
\hline & $p$ & 0.05 & 0.29 & 0.84 & 0.58 & 0.37 & 0.71 & 0.86 & \\
\hline \multirow{2}{*}{$\begin{array}{l}\text { GP } \\
\text { A }\end{array}$} & $r$ & $-0.19 *$ & 0.07 & $-.179^{*}$ & 0.12 & 0.12 & 0.01 & 0.10 & 0.11 \\
\hline & $p$ & 0.02 & 0.37 & 0.03 & 0.15 & 0.15 & 0.88 & 0.22 & 0.20 \\
\hline
\end{tabular}

Correlation coefficient; ${ }^{1} p$-value; * significant at $p<0.05$; **significant at $p<0.01$; ***significant at $p<0.001$.

\section{Discussion}

The purpose of undergraduate nursing education is to help students in acquiring the unique knowledge, skills and attitudes of the profession During the processes of education nursing students struggle in acquiring the different kinds of information because nursing science requires a variety of subjects regarding medical, nursing, humanities, psychology, human resources even statistics which in part need a multitasks of thinking, creativity and cognitive abilities ${ }^{(11)}$. With considering to the presence of a variety of individual differences that must be of concern to classroom teachers as academic ability, achievement level, brain lateralization dominance and learning style a struggling from the teacher to identify specific instructional events that will be attractive to a specific type of student become mandatory.

Previous research ${ }^{(12)}$ demonstrated that students are capable of mastering skills and acquiring information if they are taught through instructional methods that complement their hemispheric preference which will be reflected on their academic achievement and performance. Current study was carried out in an attempt to investigate the hemispheric brain dominance among nursing students in Egypt and its effect on their academic achievements.

Results of the present study revealed that the mean age of the studied participants was 20.8 years and near half of the sample were the middle birth order, and their father were university educated, while one third of their mothers were university educated. Regarding the hobbies of the participants it was a music for one third of them and art for only one quarter. About one third of the studied participants preferred a medicine specialty before joining nursing. Near to two thirds of the students were right brain dominance this comes in line with Saleh ${ }^{(13)}$ who find that students majoring in nursing tended to be right brain dominance.

This study revealed a statistical significant difference between the hemispherical brain dominance and the student's academic achievement in form of grade point average it can be justified by the fact that the way the student's brain deal with the information affect the way of utilization and recalling which will be in part affect 
on their academic performance and achievements , this result contradicted with Keat etal ${ }^{(3)}$, Kok ${ }^{(14)}$ and Singh (15) who found that brain dominance has no effect on the student's achievement in mathematics and English .

Also the results found a positive correlation between birth order, preferred specialty before joining to nursing and grade point average and academic achievement in contrast to this finding Julia et al ${ }^{(16)}$ did not find any relation or effect for the birth order on the characteristics of the personality, but regarding preferred specialty Saleh ${ }^{(13)}$ found a strong relation between brain dominance and academic majors.

\section{Conclusion}

This study was conducted in order to investigate the hemispherical brain dominance and its relation with the academic achievements among nursing students. The study revealed that about two thirds of the students were right brain dominance with grade point average 3.69, also a statistical significance difference was found between brain dominance and academic achievement, while a statistical correlation was found between birth order, preferred specialty and academic achievement with brain dominance.

\section{Recommendation}

Up on the findings of the current study the following recommendations are summarized as

1- Better understanding of the student's interest, abilities and hemispheric brain dominance help students and steer them toward filed of academic majors that are compatible with their interest.

2- The teacher should take the learners 'different interests and aptitude into consideration as a heterogeneous group during teaching processes.

3- Further research is recommended using large group size, both sexes and different settings.

Limitations of the study:

1- Small group size

2- Sample of the study was limited to female students only

3- Only one setting was included in the study

\section{References}

[1] www.hawail.edu/bemorten/Hemisphireicity/HemDefiend-htm

[2] Ali R \& Kor Liew. Association between brain hemisphericity ,learning styles and confidence in using graphics calculator for mathematics . .Eurasia Journal of mathematics Science and Technology. 2007;3(2):127-131

[3] Keat T, Kumor V, Shaki M, Akmal N\& Xuan L. The relationshipbetween brain dominance and academic performance .Acrosssectional study. British Journal of medicine and medical research . 2016;13(6):1-9

[4] www.oxofordbiblograhies.com /view/document/obo

[5] Gemaeay E, Behilk S, Kanona A\& Mansour E. self -concept and academic achievementamong nursing students ..life science journal . 2013;10(1) http://www.lifescience.com

[6] Richard P\& Deirdre J. Students attendance and academic performance in undergraduate obstetrics/ gynecology clinical rotations. The journal of American medical association.2013:310(21):2282-2288

[7] Singh P. interaction effect of brain hemispheric dominance and self-concept on academic achievement in mathematics. International journal of engineering and science $.2015 ; 5(9): 28-32$ www.researchinventy.com

[8] Oflaz M. The effect of right brain dominance in language learning .Procedia Social and Behavioral Science.2011;15;1507-1513 www.sciencedirect

[9] Ram K \& Su-Jeong H. Critical thinking and communication skills in nursing students .Advanced science and technology letters .2016; 128 (health \& nursing ) 33-37 http://dx.doi.org/10.14257/astl.2016.128.7

[10] Torrance P \& Mcarthy M . Hemispherical brain dominance scale .1980 .http://www.Roger Taylor.com

[11] Cronenwett L, Sherwood G, Barnsteiner J, Disch J\& Mitchell P.Quality and safety education for nurses .Nursing Outlook 2007;55: $122-131$.

[12] Neal B .Left or right : Which part of the brain do you side with ? 2013 .http://www.td.org/publications/Blogst/L-and-D-Blog/2013

[13] Saleh A .Brain hemisphericity and academic Majors: Acrrelation study .2001; http://www.freepatentsonline.com

[14] Kok I .Listening comprehension achievement and brain dominance .Procedia - social and behavioral science . 2014; 122: 329-334 www.sciencedirect.com

[15] Singh P. Interaction effect of brain hemispheric dominance and study on academic achievement in mathematics . International journal of applied research .2015;1(11):746-750

[16] Julia M , Boris E \& Stefac C. Examining the effects of birth order on personality .Psychological and cognitive science PNAS.2015; 112(46) www.pnas.org/cog/doi/10.1073/pnas.1506451112 